\title{
Up in the air: drone images reveal underestimation of entanglement rates in large rorqual whales
}

\author{
Christian Ramp ${ }^{1,2, *}$, David Gaspard ${ }^{1}$, Katherine Gavrilchuk ${ }^{1}$, Miranda Unger ${ }^{1}$, \\ Anna Schleimer ${ }^{1,2,3}$, Julien Delarue ${ }^{1}$, Scott Landry ${ }^{4}$, Richard Sears ${ }^{1}$ \\ ${ }^{1}$ Mingan Island Cetacean Study, St Lambert, J4P 1T3, QC, Canada \\ ${ }^{2}$ Sea Mammal Research Unit, University of St Andrews, Fife KY16 8LB, UK \\ ${ }^{3}$ Marine Evolution and Conservation, Groningen Institute for Evolutionary Life Sciences, University of Groningen, 9700 CC, \\ Groningen, The Netherlands \\ ${ }^{4}$ Center for Coastal Studies, Provincetown, 02657, MA, USA
}

\begin{abstract}
Entanglement in fishing gear is a significant threat to many cetaceans. For the 2 largest species, the blue whale Balaenoptera musculus and the fin whale B. physalus, reports of entangled individuals are rare, leading to the assumption that entanglements are not common. Studies of interaction with fisheries in other species often rely on the presence of scars from previous entanglements. Here, scar detection rates were first examined in humpback Megaptera novaeangliae, fin and blue whales using standard vessel-based photo-identification photographs collected between 2009 and 2016 in the Gulf of St. Lawrence, Canada. We then examined aerial images of fin whales collected with a drone in 2018 and 2019 and compared both methods. Entanglement rates were $6.5 \%$ for fin and $13.1 \%$ for blue whales using photo-identification images of individuals. Prominent scarring was observed around the tail and caudal peduncle, visible only when animals lifted those body sections above water when diving. For the small subset of pictures which captured the entire caudal peduncle, entanglement rates ranged between $60 \%$ for blue and $80 \%$ for fin whales. This result was similar to the $85 \%$ entanglement rate estimated in humpback whales. The assessment of aerial-based photography yielded an entanglement rate of 44.1 to $54.7 \%$ in fin whales. Scars were always around the peduncle, often the tail, rarely the dorsal fin and never around the pectoral fins, while the mouth cannot be examined from above. Thus, in species that do not regularly expose their tail or peduncle, aerial imagery is the preferred method to quantify entanglement rates by assessment of scars.
\end{abstract}

KEY WORDS: Entanglement $\cdot$ Fin whale $\cdot$ Blue whale $\cdot$ Humpback whale $\cdot$ Aerial imagery

\section{INTRODUCTION}

Entanglement in fishing gear is one of the main anthropogenic threats for large cetaceans, causing injuries and death (Read et al. 2006, Cassoff et al. 2011, Knowlton et al. 2012, Robbins et al. 2015, Corkeron et al. 2018, Sharp et al. 2019). Highly productive marine areas, particularly on the continental shelf and in coastal waters, attract both fisheries and marine species, increasing the risk of overlap and associated negative impacts (Pauly 2009). While

\footnotetext{
*Corresponding author: cr43@st-andrews.ac.uk
}

many cetacean species sustain non-lethal and lethal impacts from fishing gear entanglement (Read et al. 2006), certain vulnerable species such as the North Atlantic right whale Eubalaena glacialis and the vaquita Phocoena sinus are now facing extinction due to this continuing threat (Rojas-Bracho \& Taylor 1999, Kraus et al. 2005, 2016).

Entanglement in fishing gear can be fatal within a relatively short time frame for small cetaceans (Lien 1994, Cassoff et al. 2011), as their small size may reduce chances of freeing themselves or merely sur-

() The authors 2021. Open Access under Creative Commons by Attribution Licence. Use, distribution and reproduction are unrestricted. Authors and original publication must be credited. 
facing to breathe (Benjamins et al. 2012). For larger cetaceans, such as the North Atlantic right whale, entanglement can last for extended periods (weeks to months) (Moore et al. 2006). Long-term entanglements restrain mobility, reduce feeding ability, increase risk of infections and may result in mortality (Cassoff et al. 2011). Even entanglement events not leading to direct mortality can have significant impacts on marine species, e.g. increased drag of gear can destabilize energy balance and result in decreased survival and reproductive rates over the life-span of the animal (Moore et al. 2006, Knowlton et al. 2012, van der Hoop et al. 2013, 2016, 2017, Robbins et al. 2015, Pettis et al. 2017).

The risks and effects of entanglement are well studied in some baleen whale populations, particularly the Gulf of Maine humpback whale Megaptera novaeangliae population (Robbins 2009, 2012) and the North Atlantic right whale (Kraus 1990, Knowlton et al. 2012). These population-wide entanglement studies are mainly based on survivors, i.e. the number of animals bearing scars from previous entanglement events. Only a small proportion of entanglement events are witnessed and reported — an estimated $5.7 \%$ in Gulf of Maine humpback whales (Robbins 2009); this number is unknown in right whales. The actual number of whales becoming entangled is difficult to estimate given our inability to document all entanglement cases. For instance, entangled whales may never be seen due to reduced human presence in certain areas. If they drown at depth, carcasses may sink before being discovered, and even if found, entangled whales may not be reported for various reasons (Read et al. 2006, Cassoff et al. 2011). Overall, $82.9 \%$ of the North Atlantic right whale population were estimated to have been entangled at least once, and an average of $15.5 \%$ of individuals become entangled every year (Knowlton et al. 2012). Similarly, $64.9 \%$ of the Gulf of Maine humpback whale population shows scars from previous entanglement events, with $12.1 \%$ acquiring new entanglement scars annually (Robbins 2009).

For most populations of baleen whales, entanglement rates are unknown. At the species level it is estimated that very few entangled minke whales Balaenoptera acutorostrata survive entanglement events due to their size (Kot et al. 2009); 60.0\% of entangled minke whales around Newfoundland died (DFO 2010, Benjamins et al. 2012), but we do not know the affected proportion of any minke whale populations. Species with a more coastal distribution, such as right, humpback and minke whales, are more affected due to the higher density of fishing effort along the coast (Pauly 2009).
Large rorqual whales, including blue B. musculus and fin whales $B$. physalus, are thought to be less at risk of entanglement due to their more pelagic distribution during part of the year and their greater size and strength, which allows them to shed and/or break free of gear more easily (National Marine Fisheries Service 1998, 2010, Gregr et al. 2006, Beauchamp et al. 2009). These assumptions have led to the perception that entanglement in fishing gear is a low risk to the recovery of these species in North American Recovery and Action Plans (National Marine Fisheries Service 2010, DFO 2016, 2018).

Fishing gear, such as ropes and nets, can become attached to various body parts, most notably in the mouth, around the pectoral fins, the dorsal fin and around the caudal peduncle and tail (Kraus 1990, Knowlton \& Kraus 2001, Robbins \& Mattila 2004, Johnson et al. 2005). When cetaceans surface to breath, the mouth and pectoral fins usually remain under water in all species, making scarring difficult to detect in those areas. Humpback and right whales often lift their tail during the terminal dives, making this area consistently visible above the water surface. Scars on the caudal peduncle are therefore more likely to be observed in these 2 latter species compared to other species that rarely reveal the peduncle or fluke as they dive, such as blue, fin and minke whales. For example, the estimate that $10 \%$ of the North Atlantic blue whales carry scars from previous entanglements results from an earlier version of the same photo-ID data set used in the present study, but without correction for documented body part (Beauchamp et al. 2009). All other management documents for fin and blue whales assume entanglements as rare or judge the risk of interaction with fishing gear as low (National Marine Fisheries Service 1998, 2010, Gregr et al. 2006, DFO 2016, 2018).

Here, we investigated this potential bias in speciesspecific entanglement rate estimates by comparing the scarring rates of 3 species of rorqual whales - the humpback, the fin and the blue whale, all co-occurring in the Gulf of St. Lawrence (GSL) during the summer feeding season. We assume these species are exposed to a comparable degree of fishing effort, at least during part of the summer feeding season. Firstly, we estimated entanglement scarring rates using standard vessel-based photo-identification (photo-ID) images for all 3 rorqual species between 2009 and 2016. The estimated entanglement rates were compared between a species which regularly exposes its caudal peduncle and tail, i.e. the humpback whale, and species which rarely expose this body region, i.e. blue and fin whales. Secondly, for 
the first time, we used aerial photo-ID images of fin whales taken from small remotely piloted aerial systems (RPAS), commonly referred to as drones, in 2018 and 2019 to estimate entanglement scarring rates when the entire dorsal area of the body, including the fluke and caudal peduncle, is visible for this species. We hypothesized that the true entanglement rate in fin whales is currently underestimated using standard vessel-based photo-ID images because the body parts most prone to scarring from entanglements remain underwater and out of sight.

\section{MATERIALS AND METHODS}

\subsection{Study area}

Mingan Island Cetacean Study (MICS) researchers have conducted field studies on rorqual whales in the GSL since 1979 and maintain photo-ID catalogues for blue, fin and humpback whales for that area. The GSL is a semi-enclosed sea with seasonal ice coverage and a highly productive ecosystem that attracts many marine predators as well as human fishing activities
(Koutitonsky \& Bugden 1991, Simard \& Lavoie 1999). The principal study areas within the Gulf are the St. Lawrence Estuary, around the tip of the Gaspe Peninsula, the Sept-Iles region and the Jacques Cartier Passage (JCP); the latter being the area with the most consistent effort since 1979 (Fig. 1).

\subsection{Data collection}

\subsubsection{Vessel-based photo-data}

The primary study period in the JCP spanned annually from the beginning of June to the end of September, although in some years effort started in May and ended in December. Blue, fin and humpback whales were approached using rigid-hulled inflatable vessels and photographed by MICS researchers and their collaborators using standard vessel-based photo-ID techniques (Katona \& Whitehead 1981, Agler et al. 1990, Sears et al. 1990). Vesselbased photo-ID focuses on the body parts with contrasting natural pigmentation patterns displayed by all rorquals during regular surfacing sequences, such

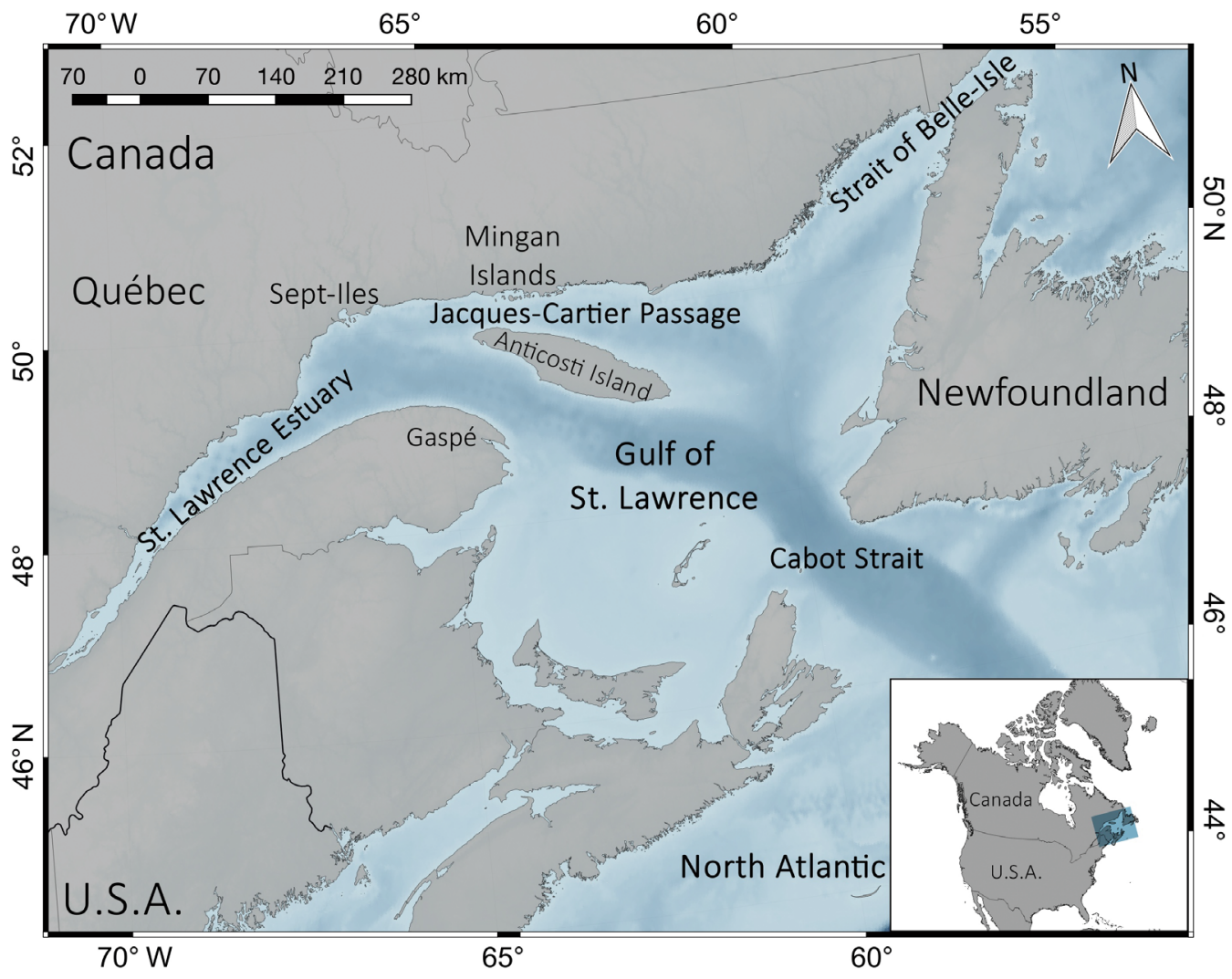

Fig. 1. Gulf of St. Lawrence area, showing the 4 primary data collection locations: the St. Lawrence Estuary, the waters off Gaspe and Sept Iles and the Jacques-Cartier-Passage (JCP). Most data were collected in the JCP 
as the flanks of blue and fin whales and the tail (fluke) of humpback whales (Fig. 2). The vesselbased photo-ID methods and data processing for these 3 species have been described in previous work (Sears et al. 1990, Ramp et al. 2006, 2010, 2014, Schleimer et al. 2019). MICS began taking additional vessel-based images in 2009 to capture the peduncle area of the 3 species and investigate the proportion of individuals with scars from previous entanglement events. While taking the last respiration in a diving sequence, these rorqual species arch their back and expose more of their body above water (Fig. 2b). In fluking species like the humpback whale, the entire side, including the fluke insertion point and the leading edge of the tail, is visible (Robbins \& Mattila 2004). For humpback whales, we selected photos of all individuals which displayed the entire tail during a dive. For fin and blue whales, we distinguished between 3 categories of individuals, depending on how much of the caudal peduncle was visible above the surface (Fig. 3). Category I showed approximately half the caudal peduncle from the dorsal fin
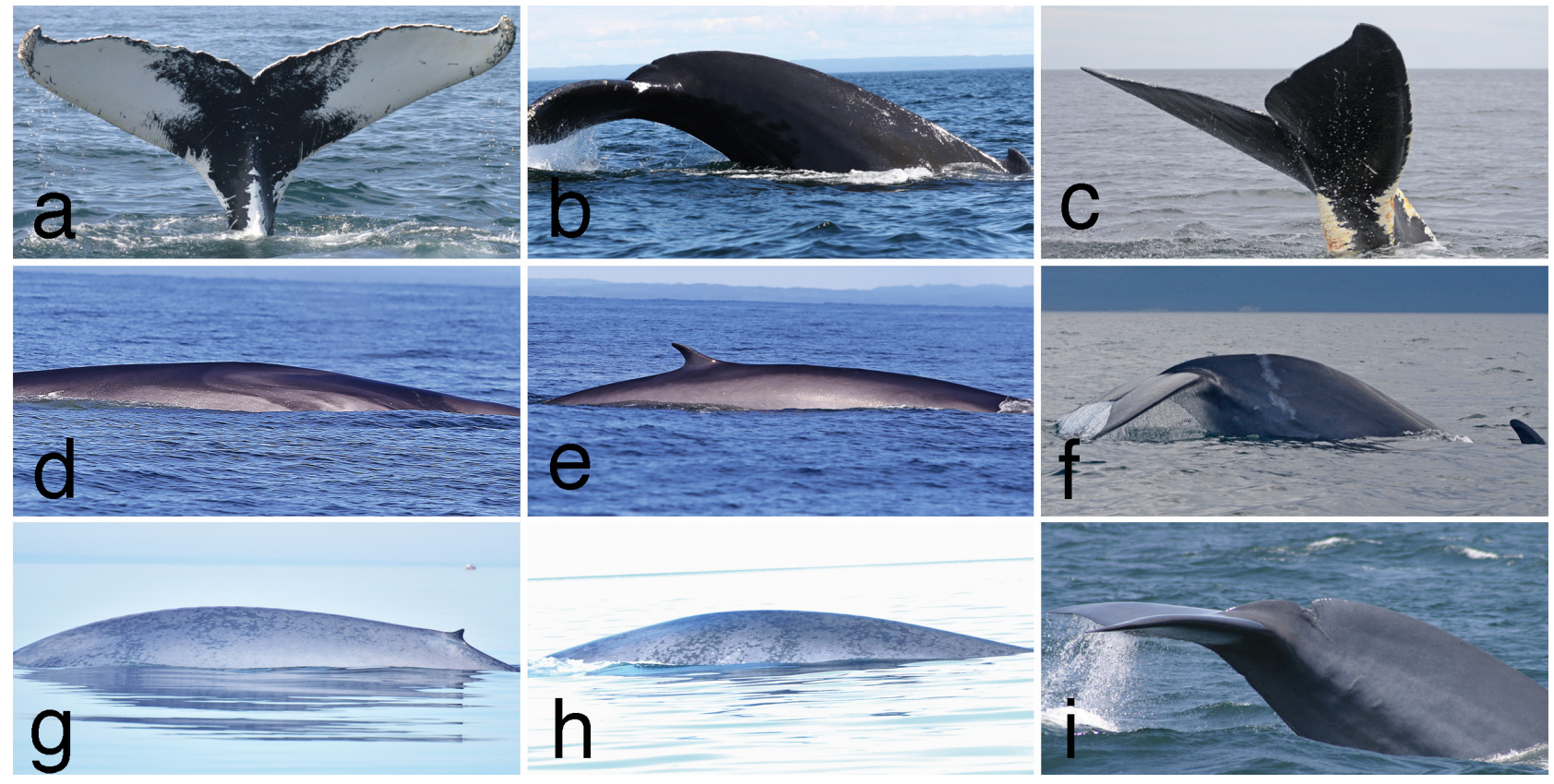

Fig. 2. Photo data used in this study: (a) ventral side of a tail (or fluke) of a humpback whale at terminal dive used for individual identification; (b) tailstock (or caudal peduncle), insertion point and leading edge of fluke of a humpback whale; (c) right side view of a right whale tail and tailstock showing prominent scars; (d) typical photo-identification pictures of a fin whale showing the right-side front with pigmentation and (e) dorsal fin; (f) right side caudal peduncle and fluke of a fin whale; (g) typical photo-identification pictures of a blue whale's left side dorsal and (h) left side front showing mottled pigmentation pattern; (i) right side caudal peduncle and fluke with insertion point of a blue whale

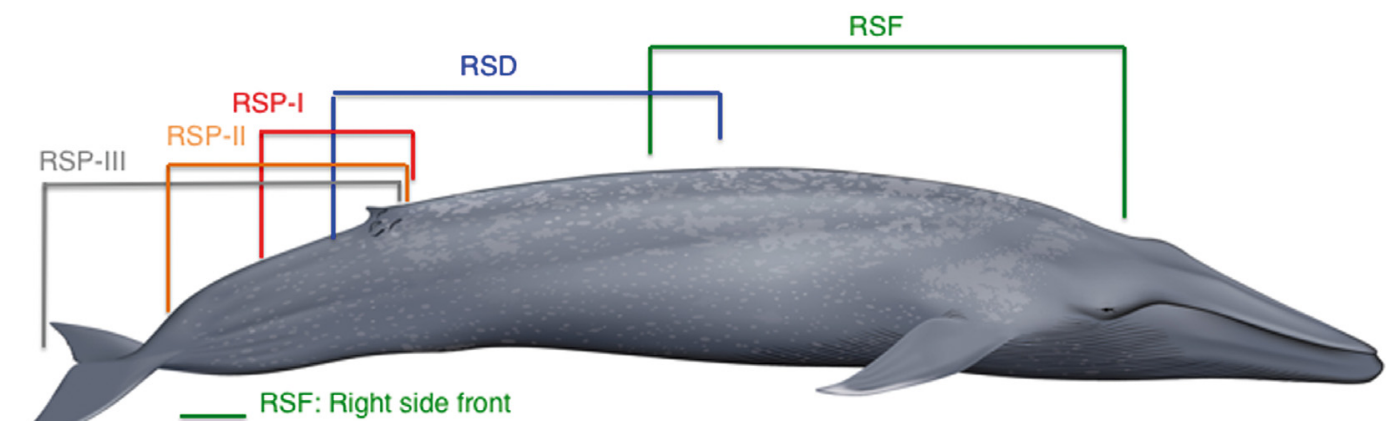

RSF: Right side front

RSD: Right side dorsal RSP-I: Right side peduncle (half) RSP-II: Right side peduncle until insertion RSP-III: Right side peduncle including insertion point \& leading edge of fluke
Fig. 3. Body parts of blue whale and fin whale (not shown) used for photo-identification and category scarring analysis. The same distinction was applied to the left side for blue whales. Original drawing by Daniel Grenier 
backwards. Category II showed the caudal peduncle almost entirely, but without the insertion point, and Category III included the insertion point and leading edge of the tail (Figs. 3, 4e,f, \& 5).

\subsubsection{Aerial-based photo data}

Aerial photo data were collected using an RPAS operated by a Transport Canada certified pilot from a vessel. For this analysis, we focused on fin whales due to their predictable spatiotemporal occurrence. The objective was to photo-identify individuals from above and obtain high definition pictures/videos of

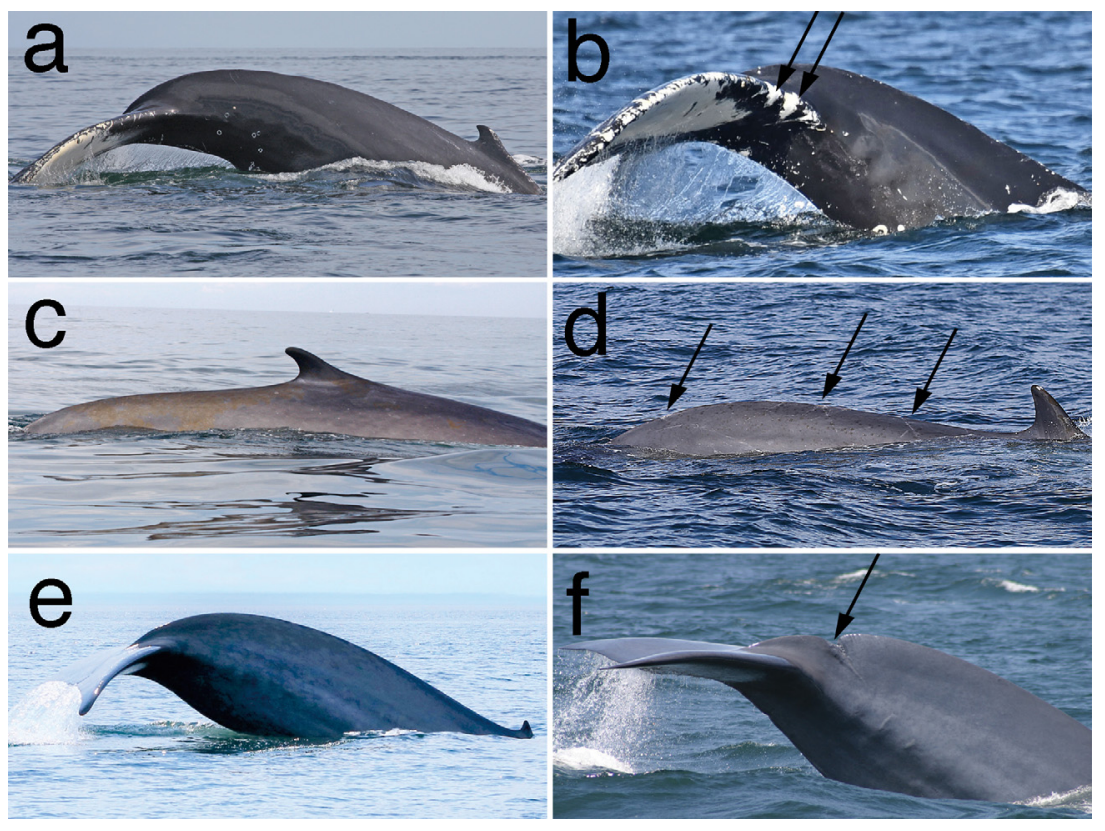

Fig. 4. Caudal peduncle pictures with scar categories for the 3 study species: (a) humpback whale with some marks on the leading edge (Score 1; unknown origin); (b) humpback whale with clear entanglement scars on leading edge and insertion point (Score 3); (c) fin whale with no marks (Score 0); (d) fin whale with typical wrapping marks (Score 2); (e) blue whale without marks (Score 0); and (f) blue whale with clear laceration scar (Score 3). Arrows show scars

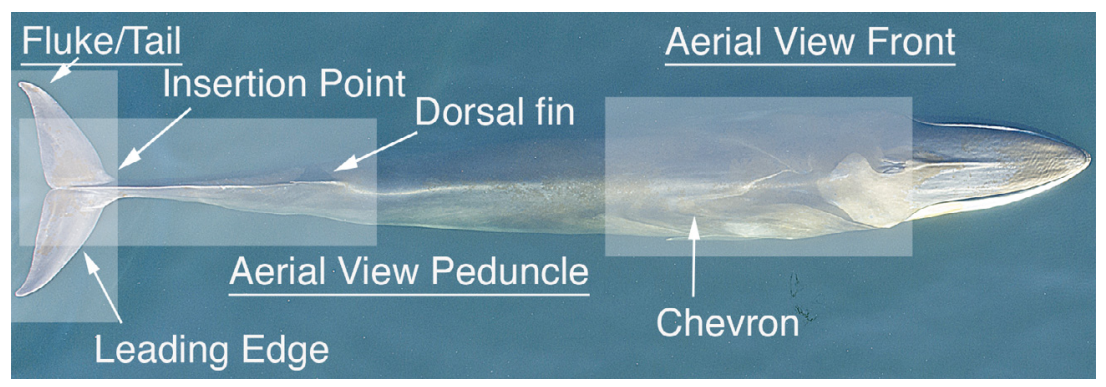

Fig. 5. Aerial view of a fin whale with 3 highlighted body parts used for this study: aerial view front, aerial view peduncle and fluke/tail, along with some other key features used in the text the peduncle, insertion point and tail to determine if an individual showed scars. Between July and September 2018, we conducted vessel-based RPAS flights to collect fin whale footage in the JCP using a DJI Phantom 4 Pro, while in July and August 2019 we used a DJI Inspire 2 with an X5S camera.

In 2018, the RPAS camera had a 20 megapixel sensor for still photos, and ultra high definition (UHD) video resolution of $3840 \times 2160$ (approximately 8 megapixel), commonly referred to as $4 \mathrm{~K}$. While the still photographs produced higher resolution images, the trigger of the camera on the RPAS suffered from a considerable delay, and the multi-photo-burst option kept crashing the DJI application. Therefore, we collected UHD quality video footage. Video settings were as follows: 5.6 to 9.1 aperture, $1 / 200$ to $1 / 400 \mathrm{~s}$ shutter speed, 60 frames $\mathrm{s}^{-1}$, and the D-LOG colour setting, which maintained the ISO at 500 (D-LOG produces a 'flat' image, but it offers more possibilities for post-processing). Due to the restrictions mentioned above, in 2019 we upgraded to a DJI Inspire 2 with an X5S camera and filmed in 5.2K $(5280 \times 2972$ pixels), resulting in 24 frames $\mathrm{s}^{-1}$, and using the same video settings as in 2018.

In 2018, we operated under a Special Flight Operation Certificate (SFOC) by Transport Canada with 2 certified pilots, a spotter to keep the RPAS in visual line of sight at all times, and a vessel operator. The spotter also served as 'catcher' for manual retrieval of the RPAS during landing. In 2019, new regulations required new certifications for the pilots but no SFOC. We hired 2 certified pilots (one operating the RPAS, and one operating the RPAS camera). In 2019, we also had the RPAS pilots, a spotter and the vessel operator.

When we located a fin whale aggregation, we positioned the vessel within 200 to $500 \mathrm{~m}$ of the whales. We observed the general behaviour a priori to establish whether the group was travelling or staying within the area. The vessel crew launched the RPAS to fly above the 
whales, and the research vessel followed the whales at a distance of 100 to $300 \mathrm{~m}$ to remain in visual line of sight of the RPAS. Footage was obtained systematically from each individual within a group at an altitude of 5 to $10 \mathrm{~m}$ to obtain high-resolution images for analysis. The camera on the RPAS filmed the area between the head/chevron and then peduncle/tail several times during a surfacing before switching to the next animal. Following preliminary flight trials, we restricted the filming to excellent weather conditions. Although the pilots were technically able to launch, fly and recover the RPAS in higher winds (in excess of 20 knots), the resulting images were not useful. The aim was to film the body parts remaining under the surface, and any slight ripple of the water distorted the images making scar detection unreliable. We therefore only filmed in Beaufort Sea state 1 or less (less than 4 knots of wind speed) and clear to partly cloudy conditions. Overcast skies (cloud cover $>5$, with 0 indicating clear sky and 10 complete overcast) hindered aerial image analysis due to cloud reflection and reduced sunlight penetrating the water to illuminate the whale's body (see Figs. S1, S2 \& S3 in the Supplement at www.int-res.com/articles/ suppl/n044p033_supp.pdf for examples with different light and surface conditions).

\subsection{Photo and video data selection}

For vessel-based scarring assessment, we used only high or very high quality pictures from the existing photo-ID catalogues (Ramp et al. 2006, 2010, 2014, Schleimer et al. 2019). We limited the analysis from 2009 to 2016, the years for which we had highresolution digital images.

For aerial-based scarring assessments, imagery of each individual was viewed frame by frame in Adobe Premiere. We then extracted 3 pictures per individual (Fig. 5): (1) the dorsal aspect of the chevron (referred to as aerial view front $[\mathrm{AVF}])$, which includes the pigmentation pattern unique to each individual; (2) the dorsal aspect of the tailstock (referred to as aerial view peduncle [AVP]), covering the area of the dorsal fin to the caudal peduncle; and (3) the dorsal aspect of the tail/fluke.

Three researchers compared AVF pictures to identify individual fin whales. Photos from individual whales that were sampled on separate occasions were combined to determine the overall sample size of individuals. Aerial imagery has been used to successfully identify individual bowhead whales Balaena mysticetus and right whales (Kraus et al. 1986, Rugh et al. 1992). We applied published methods (Agler et al. 1990) for vessel-based photo-ID pictures of fin whales, with some additions. The lower parts of the pigmentation pattern, particularly the eye stripe, the ear stripe and interstripe wash (nomenclature after Agler et al. 1990), were barely visible from above; only the upper part of the pigmentation pattern (the blaze and chevrons) was photographable. However, the chevron of both sides was visible from the air (Fig. 6) within a single frame. There was considerable variation in the way the 2 chevrons ended, from being closed to being wide apart. We observed additional pigmentation patterns, such as the 'appendix' just before the chevrons came together behind the blowholes (Fig. 6). There was usually 1 'appendix' in light pigmentation against a dark background, and it could either be connected to the chevrons or distinctly apart. In a few instances, there were 2 or none at all. We also detected additional pigmentation lines starting at the blowholes, with 2 such lines present in all observed animals (Fig. 6). The 'right blow line' was light in colouration and followed the shape of the upper blaze, leaving a thin but very distinct curvilineal dark space between the blaze and the right blow line before fading out towards the chevron. The left blow line was light in colour and meandered down the left side of the body or ended in the back of the head. We often extracted 2 pictures of the AVF, above and below the water. Focusing on the pigmentation of the dorsal aspect of the chevrons allowed us

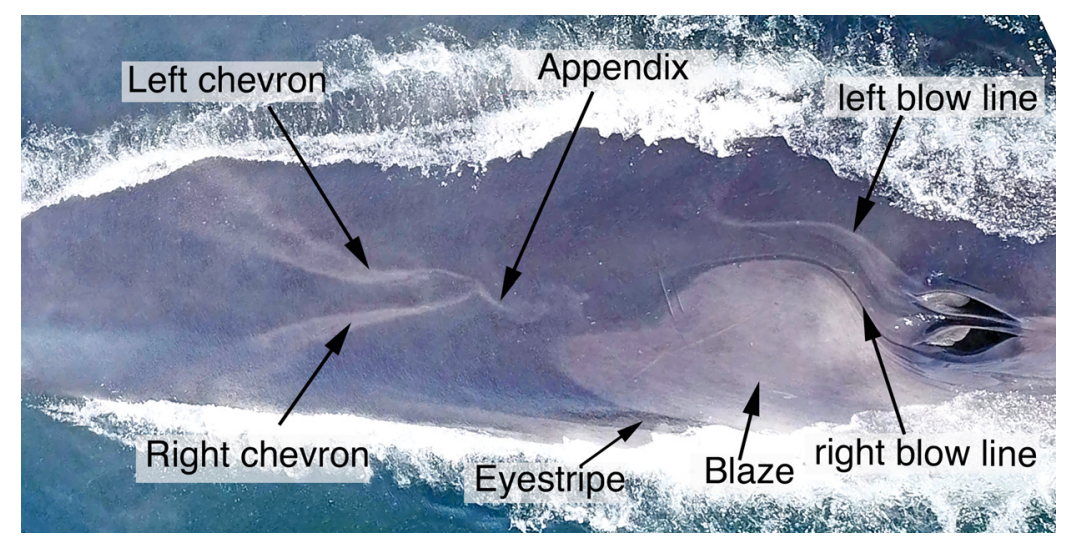

Fig. 6. Fin whale pigmentation pattern used to identify individuals from remotely piloted aerial systems imagery. Left/right chevron, blaze, and eye stripe following the description by Agler et al. (1990). We added some nomenclature such as the appendix and blow lines. All features were visible when below or above the water 
to identify a fin whale even underwater, but only under ideal weather conditions.

All pictures were classified from 1 (excellent) to 5 (very poor) for each of the following characteristics: angle, light, focus, resolution (pixel) and proportion of body in the frame. We then summed the classification values for each picture. Pictures with a total value of 5 to 7 were of excellent quality (Grade A), 8 to 10 were good quality (Grade B), 11 to 13 were medium quality (Grade $C$ ) and values greater than 14 were poor quality (Grade D). If any one of the key characteristics such as light, focus or resolution was assigned a value of 3 , the picture was automatically assigned as medium quality (Grade C), or poor quality (Grade D) if assigned a value of 4 . The AVP and fluke pictures were underwater images, so light distortion due to ripples/wavelets or the animal's wake blurred the feature. If the photo was in focus, but the outline of the features (e.g. fluke) and potential scars were not clear and sharp, the picture was rated of medium quality (Grade C).

\subsection{Photo and video grading process}

For vessel-based photo data, 2 researchers independently graded the pictures of photo-identified individuals for signs of entanglement scars, using 4 scores - 0: no scars; 1: some marks or scars but unlikely or uncertain to be from entanglement; 2 : very likely entanglement scars; and 3: definite entanglement scars (Fig. 4). The marks or scars that we considered as very likely to be from entanglements included deep lacerations and wrapping marks around the caudal peduncle and dorsal fin following previous scarring classifications (Kraus 1990, Robbins \& Mattila 2004, Knowlton et al. 2012). For fin whales, we only took pictures of the right side of the body, while in blue and humpback whales, we analyzed the left and right side separately, because we did not have photos of both sides from all sampled individuals. Since we did not find any difference in the number of scars on the right versus left side in humpback and blue whales, we pooled left and right photos of each individual to increase sample size. In the case where an individual had an uncertain mark on one side (Score 1), but a clear entanglement mark on the other (Score 3), we considered the individual as being previously entangled.

For aerial-based photo data, once the full sample size of unique animals was selected, 3 researchers independently graded pictures for signs of entanglement scars using the same 4 categories as for the vessel- based pictures (Fig. 2). The third researcher was from an outside institution and had not been involved in aerial photo collection or processing. When light or water distortion made detection of scars on aerial photos difficult, the aerial video sequence of the surfacing and dive was reviewed. The video helped confirm whether an ambiguous mark seen on the aerial photo was indeed a scar. Video footage was also consulted when the researchers graded photos from the same individual differently, which solved all but 2 cases. The remaining 2 cases were graded as not entanglementrelated scarring due to the doubts of 1 researcher.

We then sorted the batches of pictures by their quality and calculated the proportion of scarred individuals for each quality grade and for all animals combined.

\section{RESULTS}

\subsection{Vessel-based images}

Of the vessel-based photo-ID data, we had a total sample size of 191 unique individual blue whales, 322 fin whales and 112 humpback whales, all sighted since 2009. Standard photo-ID pictures (front and dorsal) were obtained from all 322 fin whales, but the number of whales for which we had data for the caudal peduncle was considerably lower. For fin whales, we had 210 individuals with Score 1 pictures, 101 Score 2 and only 5 animals with Score 3 photos showing the entire caudal peduncle (Figs. $2 \mathrm{f} \& 3$ ). This pattern was similar for blue whales, with 70 individuals in Score 1, 49 in Score 2 and 22 in Score 3. Using the standard photo-ID pictures, we found entanglement rates varied from $1.0 \%$ using the front pictures of fin whales to $10.9 \%$ using the dorsal/flank pictures of the blue whales (Fig. 7). When we combined the pictures of the 2 body parts we found $6.5 \%$ of fin whales and $13.1 \%$ of blue whales showed scars from previous entanglements. We found that as the proportion of the caudal peduncle visible in the frame increased, the number of detected entanglement scars also increased (up to $59.9 \%$ for blue and $80.0 \%$ for fin whales; Fig. 7). We obtained full peduncle pictures (Score 3) of all 112 humpback whales, and 96 $(85.7 \%)$ showed scars from previous entanglements.

\subsection{Aerial-based images}

We obtained our aerial imagery in 13 d in 2018, conducting a total of 106 flights with a combined 


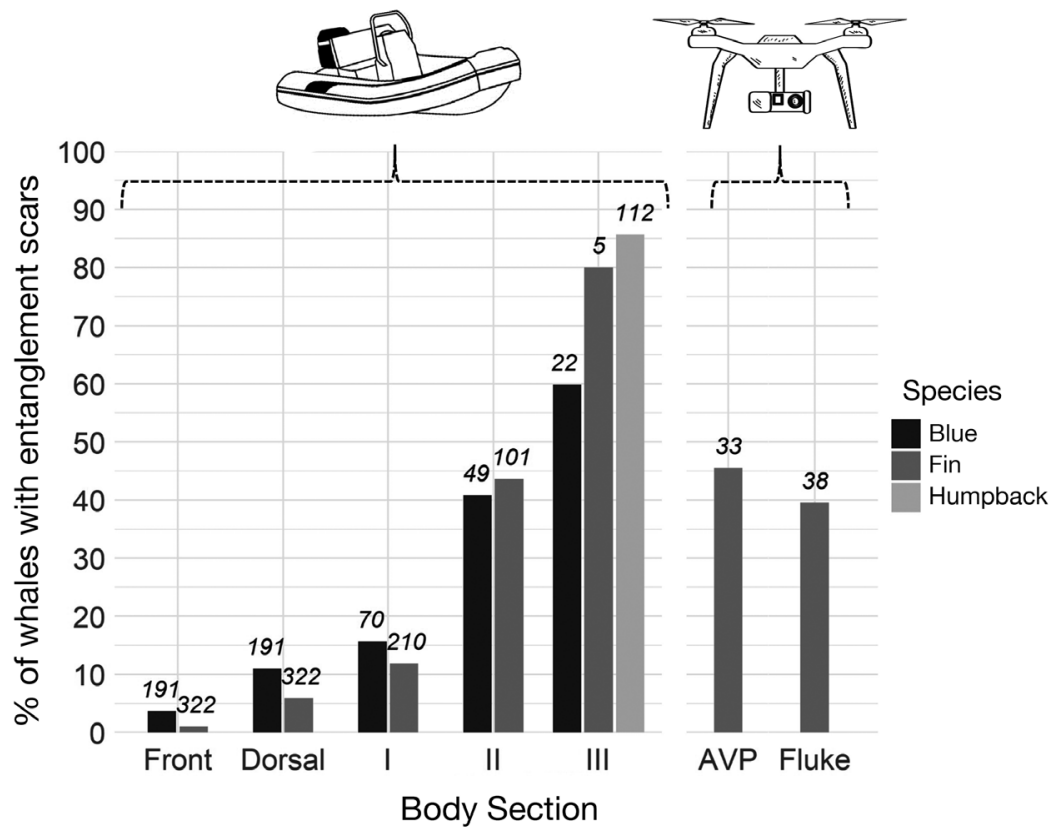

Fig. 7. Entanglement rates for different body parts of blue, fin and humpback whales in the Gulf of St. Lawrence using vessel-based and remotely piloted aerial systems (RPAS)-based pictures. Front and dorsal body sections are standard photo-ID pictures for fin and blues. Categories I, II and III describe the proportion of the visible caudal peduncle. Aerial view peduncle (AVP) and fluke are taken with a remotely piloted aerial systems. Sample size (number of individuals) listed above bars duncle. Three animals had scars visible forward of the dorsal fin. In 2019, 3 fin whales showed wrapping injuries that appeared to be recent, with injuries that were likely acquired over the summer. Based on the 43 total animals in 2019, this represents an annual entanglement rate of $6.9 \%$. Two individuals documented in 2018 were suspected of having fresh injuries, but the lower resolution images made it impossible to be certain and therefore we did not calculate the annual entanglement rate for 2018. None of the 3 whales seen in both years gained an additional scar between 2018 and 2019.

In both 2018 and 2019 we only encountered 1 blue whale $\mathrm{yr}^{-1}$, and aerial images of both individuals showed scars from previous entanglement events. These 2 individuals were already in the GSL photo-ID catalogue, and scars were not apparent on their standard vessel-based photo-ID pictures (see Fig. S4).

\section{DISCUSSION}

flight time of $17.9 \mathrm{~h}$. Altogether, we captured 264 video clips from which we extracted 363 frames from 91 fin whales. Of the 91 animals, 82 were successfully photo-identified using their unique dorsal pigmentation patters, resulting in a total of 59 unique individuals. For 35 of these individuals, we had pictures of either the fluke, the caudal peduncle or both (see Figs. S1, S2 \& S3 for examples of identification, caudal peduncle and tail pictures).

In 2019, we filmed on $12 \mathrm{~d}$, totalling $13 \mathrm{~h}$ of flight time with 276 video clips from which we extracted 576 frames. We approached 107 fin whales, or 47 unique individuals. For 43 of them, we had peduncle (AVP) and/or fluke pictures.

Combining both years gave us a sample size of 78 fin whale individuals; however, since 3 individuals were sampled in both years, our final sample size was 75. Of these 75 fin whales, 31 (or $41.3 \%$ ) had scars from previous entanglements (Table 1). For different subsets of the data, the proportion of individuals with entanglement scars ranged between 36.5 and $54.7 \%$. Examining only high quality (Grade A or B) pictures, 23 out of 42 $(54.7 \%)$ fin whales showed signs of previous entanglements. The caudal peduncle was much more likely to show entanglement scars than the fluke. Only 2 animals had scars visible on the fluke but not on the pe-
In this study, we used vessel-based photography to estimate the entanglement rates of humpback, fin and blue whales in the GSL collected between 2009 and 2016 and compared the fin whale estimate with that derived from an analysis based on aerial

Table 1. Percentage of unique, aerially sampled fin whales with scars from previous entanglements in 2018 and 2019 combined, with respect to photo quality (Grade A, B, C, or D; see Section 2.3 and Fig. 3) and body part (aerial view peduncle [AVP], fluke)

\begin{tabular}{|lccc|}
\hline & Total & $\begin{array}{c}\text { No. } \\
\text { with scars }\end{array}$ & $\begin{array}{c}\text { Percentage } \\
\text { with scars }\end{array}$ \\
\hline All fin whales $^{1}$ & 75 & 31 & 41.3 \\
Quality A, B and C & & & \\
AVP or fluke & 68 & 30 & 44.1 \\
AVP & 65 & 28 & 43.1 \\
Fluke & 63 & 23 & 36.5 \\
Quality A and B & & & \\
AVP or fluke & 42 & 23 & 54.7 \\
AVP & 33 & 15 & 48.5 \\
Fluke & 38 & 15 & 39.5 \\
${ }^{1}$ Grade A, B, C and D combined & & \\
\hline
\end{tabular}


imagery collected in 2018 and 2019. Our results confirmed the hypothesis that current entanglement estimates of non-fluking rorqual whales are biased low due to inadequate photo documentation of the body areas prone to entanglement-related scarring.

Humpback whales, which commonly expose their tail when diving, showed the highest entanglement occurrence, with over $85 \%$ of individuals photographed from vessels exhibiting scars from prior entanglement(s). Using standard vessel-based photoID pictures of fin and blue whales, the proportion of individuals with entanglement scarring varied between 1 and $11 \%$ depending on the body area examined and resulted in overall entanglement-related proportions of $6.5 \%$ for fin whales and $13.1 \%$ for blue whales, which are in line with previous estimates and show the same bias (Beauchamp et al. 2009). However, in the present study, focusing the analyses on vessel-based photographs of the caudal peduncle revealed a substantially higher proportion of animals exhibiting scars. We found that as more of the caudal peduncle was exposed, the higher the proportion, affirming the caudal peduncle as the body area most prone to visible scarring and an important target for documentation from all platforms. The entanglement rate reached up to $80 \%$ for fin whales in Category III, but was based on very few animals $(n=5)$. This elevated estimate should be interpreted with caution, because some animals might have been impaired due to the sustained injuries and were forced to lift the tail to get enough thrust to dive, thus more likely to expose this body part.

The most robust entanglement estimate based on an adequate sample size was achieved using aerial photo and video data from the RPAS. It showed that between 41.3 and $54.7 \%$ of the fin whales in the GSL exhibit scars from previous entanglement events. The estimate for the annual entanglement rate, and thus quantifying the current scale of fisheries interaction in fin whales, is $6.9 \%$. Successive years with increased sample sizes are required to confirm that estimate and could be used to monitor changes in light of management efforts. For blue whales, we would need a substantially larger sample size of aerially photographed individuals to estimate the overall prevalence of entanglement in this endangered population. It is, however, reasonable to speculate that it is comparable to fin whales, based on similar results using caudal peduncle pictures. At this time, we suggest the entanglement rate for blue whales lies between the results of Category II and III, between 40.8 and $59.9 \%$. Although more precise estimates using aerial imagery are required, it is clear that the occurrence of entanglements has so far been underestimated. Mitigation measures in recovery and action plans for fin and blue whales need to be revised.

Our entanglement estimates from aerial imagery were likely still biased low for several reasons. For one, this study was only based on live individuals that had survived entanglements and did not include mortality data, although there are multiple reports over the years of carcasses found with attached gear (COSEWIC 2019). Secondly, we were conservative in attributing scars to entanglement events; we suspect that some of the obscure marks we observed were indeed entanglement related. However, we classified them of uncertain origin in this analysis. Thirdly, minor entanglement scars may also have healed, making them more difficult to detect. Furthermore, fin whales are paler in colour than right and humpback whales, and scar tissue will have less contrast against the natural pigmentation of the body. Lastly, in one case we observed a lunge-feeding fin whale with entanglement injuries at the gape of the mouth, a body area not consistently seen and therefore not assessed in this study. The mouth is a commonly entangled body area in other species (Johnson et al. 2005), and this may also be true with fin whales. Previous assessments of gear configurations and attachment points on entangled whales found that gear becomes frequently stuck in the mouth, particularly the baleen, while the animal is feeding (Johnson et al. 2005, Cassoff et al. 2011). For most fin whale entanglements, the attachment point remains unknown; however, a study along the east coast of Canada and the USA found the majority of entanglement cases with known gear configurations affected the mouth area (Henry et al. 2012, 2015).

There are considerably fewer reports of entangled fin whales compared to humpback or right whales (Henry et al. 2012, 2015). Fin whales may carry gear farther offshore, where they would go largely undetected, or break the gear due to their greater strength (Arthur et al. 2015). Alternatively, the more fusiform body shape of fin whales, compared to humpback and right whales, may aid in shedding gear more readily. There could also be a different kind of reaction to entanglement, because they are a flight species (Ford \& Reeves 2008). Entanglement might result in an instinctive flight reaction compared to right or humpback whales, which tend to react by thrashing and rolling (Weinrich 1999, Knowlton et al. 2016). The flight response might exhaust the animal, resulting in shock and rapid death/mortality. While it might be possible that fin whales are less impacted by entanglement than right or humpback whales, the high rates deter- 
mined in this study are of concern, and the impact of fishery interaction should be included in any future stock assessment, recovery strategy and action plan.

Humpback whales in the GSL had a higher entanglement rate $(85.7 \%)$ than fin and blue whales and the results were based on a substantially larger sample size over several years. The estimate is on the upper range of other humpback whale studies, such as from the Gulf of Maine with 65\% (Robbins 2012) and Southeast Alaska with up to $71 \%$ (Neilson et al. 2009). One explanation for the higher entanglement rates in humpback whales versus fins and blues could be their particularly long pectoral fins which may become easily entangled (Lien 1994). In this study, we did not observe any scarring on flippers in sampled fin whales. Humpback whales in the GSL also occur partly in shallower, more coastal waters and may come into contact with whelk Buccinum undatum and lobster Homarus americanus fisheries. The whelk fishery operates from May to October in the GSL, overlapping with the peak occurrence of rorqual species. Fin and blue whales are most often pelagic and are likely affected by the deep-water snow crab Chionoecetes opilio fishery, which ends in the Gulf of St. Lawrence with a season from April to usually mid-July. Some humpback whales which frequent the GSL winter off the east coast of the USA (Barco et al. 2002) and might be exposed to more fisheries for a greater part of the year compared to the more pelagic blue and fin whales which might spend the winter months further offshore (Lesage et al. 2017).

Monitoring individuals from these rorqual populations in the GSL over several successive years will be required to obtain better estimates of annual entanglement rates. From data presented here, we cannot distinguish between longer-lasting entanglements and minor short-term incidents, nor in what year they occurred. Some of the scars we detected may have been acquired decades ago, while others could have been from more recent years. The 3 fin whales with fresh injuries in 2019 indicate that interaction with fishing gear persists. Short-lived or longer-lasting, any entanglement event is presumed to induce stress with a negative impact on health due to increased drag, increased risk of infection and impaired feeding capacities (van der Hoop et al. 2013, 2016, 2017 , Robbins et al. 2015).

\section{CONCLUSIONS}

Despite its limited sample size, this study provides clear indication that the occurrence of entanglement in fin whales is higher than previously estimated. We suggest that this likely applies to blue whales as well. Approximately half of the fin whales investigated had scars from previous entanglements. While we do not know the outcome of most entanglements, we know that some result in fatality. Because of this, recovery plans and strategies should include the potential effect of fishing activities on the recovery of these species. Previous studies have shown a decreasing fin whale survival rate since 2004 (Ramp et al. 2014, Schleimer et al. 2019) and a decline in abundance of the same population in the GSL (Schleimer et al. 2019). There is no evidence that the decline was caused mainly, or even at all, by entanglement, but this seems highly plausible given the impact of entanglement on other populations (Moore et al. 2006, Knowlton et al. 2012, Robbins et al. 2015). The next step is to increase the sample size to obtain a more precise entanglement estimate, particularly for the endangered blue whale. With several consecutive years of data, annual entanglement rates could be calculated to investigate what proportion of these populations gain new scars between years. Continuing the aerial data collection, or at least collecting images of the caudal peduncle from vessel-based platforms whenever possible, will also enable monitoring of the efficacy of potential mitigation measures. Aerial and vessel-based photographs of the same animals at the same time should be compared to determine what methods are better suited to detect scars on different body parts. More data could also facilitate estimation of entanglement survival rates, similar to studies on humpback and right whales (Robbins et al. 2015) and how entanglement affects reproductive rates.

While the general methodology used here applies to many areas and populations, we caution the comparison of our results to other regions, as these are site-specific estimates. The proportion of rorqual whales affected by fishing gear is highly dependent on the extent of the spatial and temporal overlap between fishing effort and whale distribution (Pauly 2009). However, in some areas, the associated increased mortality and reduced fecundity could offset any population growth and tip a population into decline.

Acknowledgements. The Mingan Island Cetacean Study (MICS) acknowledges the effort and dedication of its team members and volunteers. Without them, this long-term study would not have been possible. Sincere gratitude is extended to the dozens of individuals who kindly contributed to the study with pictures over the years. The main contributors have been the Group for Research and Education on Marine Mammals (GREMM), Le Réseau d'observation de mammifères marins (ROMM), Croisières Baie de 
Gaspé, Mériscope, DFO scientists and agents, Yves Morin, René Roy, Catherine Dubé, Jacques Gélineau. Thank you to the UAS flight crews from TerreSky, Parafilm and Drone Box who collected the aerial data. Many thanks to Henry Allison (NOAA), the Quebec Marine Mammal Emergency Response team (RQUMM) for information related to entanglements, data on mortalities and fruitful discussions. Heather Pettis (New England Aquarium) and Michael Moore (Woods Hole Oceanographic Institute) greatly improved an earlier version of the manuscript with their reviews and comments. The research was conducted under permits and approvals from the Canadian Department of Fisheries and Oceans (DFO), Transport Canada, as well as the Animal Welfare and Ethics Committee of the School of Biology at the University of St. Andrews. The aerial part of the study in 2018 and 2019 was funded by DFO.

\section{LITERATURE CITED}

Agler BA, Beard JA, Bowman RS, Corbett HD and others (1990) Fin whale (Balaenoptera physalus) photographic identification: methodology and preliminary results from the Western North Atlantic. Rep Int Whaling Comm Spec Issue 12:349-356

Arthur LH, McLellan WA, Piscitelli MA, Rommel SA and others (2015) Estimating maximal force output of cetaceans using axial locomotor muscle morphology. Mar Mamm Sci 31:1401-1426

Barco SG, McLellan WA, Allen JM, Asmutis-Silvia RA and others (2002) Population identity of humpback whales (Megaptera novaeangliae) in the waters of the US midAtlantic states. J Cetacean Res Manag 4:135-141

Beauchamp J, Bouchard H, de Margerie P, Otis N, Savaria JY (2009) Recovery strategy for the blue whale (Balaenoptera musculus), Northwest Atlantic population, in Canada [FINAL]. Species at Risk Act Recovery Strategy Series. Fisheries and Oceans Canada, Ottawa

Benjamins S, Ledwell W, Huntington J, Davidson AR (2012) Assessing changes in numbers and distribution of large whale entanglements in Newfoundland and Labrador, Canada. Mar Mamm Sci 28:579-601

Cassoff RM, Moore KM, McLellan WA, Barco SG, Rotstein DS, Moore MJ (2011) Lethal entanglement in baleen whales. Dis Aquat Org 96:175-185

Corkeron P, Hamilton P, Bannister J, Best P and others (2018) The recovery of North Atlantic right whales, Eubalaena glacialis, has been constrained by humancaused mortality. R Soc Open Sci 5:180892

COSEWIC (Committee on the Status of Endangered Wildlife in Canada) (2019) COSEWIC assessment and status report on the fin whale Balaenoptera physalus, Atlantic population and Pacific population, in Canada. Committee on the Status of Endangered Wildlife in Canada, Ottawa

DFO (Fisheries and Oceans Canada) (2010) Identification d'innovation en vue de limiter les prises accessoires de mammiferes marin. Fisheries and Oceans Canada, Ottawa

DFO (2016) Partial action plan for blue, fin, sei and north Pacific right whales (Balaenoptera musculus, B. physalus, B. borealis, Eubalaena japonica) in Canadian Pacific waters. Species at Risk Act Action Plan Series. Fisheries and Oceans Canada, Ottawa

DFO (2018) Action plan for the blue whale (Balaenoptera musculus), northwest Atlantic population, in Canada
[Proposed]. Species at Risk Act Recovery Strategy Series. Fisheries and Oceans Canada, Ottawa

Ford JKB, Reeves R (2008) Fight or flight: antipredator strategies of baleen whales. Mammal Rev 38:50-86

Gregr EJ, Calambokidis J, Convey L, Ford JKB, Perry RI, Spaven L, Zacharias M (2006) Proposed recovery strategy for blue, fin, and sei whales (Balaenoptera musculus, B. physalus, B. borealis) in Pacific Canadian Waters. In Species at Risk Act Recovery Strategy Series. Fisheries and Oceans Canada, Vancouver

Henry AG, Cole TVN, Garron M, Hall L, Ledwell W, Reid A (2012) Mortality and serious injury determinations for baleen whale stocks along the Gulf of Mexico, United States east coast and Atlantic Canadian provinces, 2006-2010. Northeast Fish Sci Cent Ref Doc 12-11

Henry AG, Cole TVN, Hall L, Ledwell W, Morin D, Reid A (2015) Mortality determinations for baleen whale stocks along the Gulf of Mexico, United States east coast, and Atlantic Canadian provinces, 2007-2011. Northeast Fish Sci Cent Ref Doc 13-18

Johnson A, Salvador G, Kenney J, Robbins J, Kraus S, Landry S, Clapham P (2005) Fishing gear involved in entanglements of right and humpback whales. Mar Mamm Sci 21:635-645

K Katona S, Whitehead H (1981) Identifying humpback whales using their natural markings. Polar Rec 20:439-444

Knowlton AR, Kraus SD (2001) Mortality and serious injury of northern right whales (Eubalaena glacialis) in the western North Atlantic Ocean. J Cetacean Res Manag (Spec Issue) 2:193-208

Knowlton AR, Hamilton PK, Marx MK, Pettis HM, Kraus SD (2012) Monitoring North Atlantic right whale Eubalaena glacialis entanglement rates: a $30 \mathrm{yr}$ retrospective. Mar Ecol Prog Ser 466:293-302

Knowlton AR, Robbins J, Landry S, McKenna HA, Kraus SD, Werner TB (2016) Effects of fishing rope strength on the severity of large whale entanglements. Conserv Biol 30: 318-328

Kot BW, Ramp C, Sears R (2009) Decreased feeding ability of a minke whale (Balaenoptera acutorostrata) with entanglement-like injuries. Mar Mamm Sci 25:706-713

Koutitonsky V, Bugden GL (1991) The physical oceanography of the Gulf of St. Lawrence: a review with emphasis on the synoptic variability of the motion. Can Spec Publ Fish Aquat Sci 113:57-90

Kraus SD (1990) Rates and potential causes of mortality in North Atlantic right whales (Eubalaena glacialis). Mar Mamm Sci 6:278-291

Kraus SD, Moore KE, Price CA, Crone MJ, Watkins WA, Winn HE, Prescott JH (1986) The use of photographs to identify individual North Atlantic right whales. Rep Int Whaling Comm (Spec Issue) 10:145-151

Kraus SD, Brown MW, Caswell H, Clark CW and others (2005) North Atlantic right whales in crisis. Science 309: 561-562

Kraus SD, Kenney RD, Mayo CA, McLellan WA, Moore MJ, Nowacek DP (2016) Recent scientific publications cast doubt on North Atlantic right whale future. Front Mar Sci 3:137

* Lesage V, Gavrilchuk K, Andrews RD, Sears R (2017) Foraging areas, migratory movements and winter destinations of blue whales from the western North Atlantic. Endang Species Res 34:27-43

Lien J (1994) Entrapments of large cetaceans in passive inshore fishing gear in Newfoundland and Labrador 
(1979-1990). Rep Int Whal Comm Spec Issue 15: 149-157

Moore MJ, Bogomolni A, Bowman R, Hamilton PK and others (2006) Fatally entangled right whales can die extremely slowly. Conf Proc OCEANS 2006, Boston, MA

National Marine Fisheries Service (1998) Recovery plan for the blue whale (Balaenoptera musculus). National Marine Fisheries Service, Silver Spring, MD

National Marine Fisheries Service (2010) Final recovery plan for the fin whale (Balaenoptera physalus). National Marine Fisheries Service, Silver Spring, MD

Neilson JL, Straley JM, Gabriele CM, Hills S (2009) Nonlethal entanglement of humpback whales (Megaptera novaeangliae) in fishing gear in northern Southeast Alaska. J Biogeogr 36:452-464

Pauly D (2009) Beyond duplicity and ignorance in global fisheries. Sci Mar 73:215-224

* Pettis HM, Rolland RM, Hamilton PK, Knowlton AR, Burgess EA, Kraus SD (2017) Body condition changes arising from natural factors and fishing gear entanglements in North Atlantic right whales Eubalaena glacialis. Endang Species Res 32:237-249

Ramp C, Bérubé M, Hagen W, Sears R (2006) Survival of adult blue whales (Balaenoptera musculus) in the Gulf of St. Lawrence, Canada. Mar Ecol Prog Ser 319: 287-295

Ramp C, Bérubé M, Palsbøll P, Hagen W, Sears R (2010) Sex-specific survival in the humpback whale Megaptera novaeangliae in the Gulf of St. Lawrence, Canada. Mar Ecol Prog Ser 400:267-276

Ramp C, Delarue J, Bérubé M, Hammond PS, Sears R (2014) Fin whale survival and abundance in the Gulf of St. Lawrence, Canada. Endang Species Res 23:125-132

Read AJ, Drinker P, Northridge S (2006) Bycatch of marine mammals in US and global fisheries. Conserv Biol 20: 163-169

Robbins J (2009) Scar-based inference into Gulf of Maine humpback whale entanglement: 2003-2006. Report to the Northeast Fisheries Science Center, National Marine Fisheries Service, Woods Hole, MA

Robbins J (2012) Scar-based inference into Gulf of Maine humpback whale entanglement: 2010. Report to the National Marine Fisheries Service. Center for Coastal Studies, Provincetown, MA

Robbins J, Mattila D (2004) Estimating humpback whale

Editorial responsibility: Brendan Godley, University of Exeter, Cornwall Campus, UK
(Megaptera novaeangliae) entanglement rates on the basis of scar evidence. Report to the Northeast Fisheries Science Center, National Marine Fisheries Service, Woods Hole, MA

Robbins J, Knowlton AR, Landry S (2015) Apparent survival of North Atlantic right whales after entanglement in fishing gear. Biol Conserv 191:421-427

Rojas-Bracho L, Taylor BL (1999) Risk factors affecting the vaquita (Phocoena sinus). Mar Mamm Sci 15:974-989

Rugh DJ, Braham HW, Miller GW (1992) Methods for photographic identification of bowhead whales, Balaena mysticetus. Can J Zool 70:617-624

Schleimer A, Ramp C, Delarue J, Carpentier A and others (2019) Decline in abundance and apparent survival rates of fin whales (Balaenoptera physalus) in the northern Gulf of St. Lawrence. Ecol Evol 9:4231-4244

Sears R, Williamson JM, Wenzel FW, Bérubé M, Gendron D, Jones P (1990) Photographic identification of the blue whale (Balaenoptera musculus) in the Gulf of St. Lawrence, Canada. Rep Int Whal Comm Spec Issue 12: 335-342

Kharp SM, McLellan WA, Rotstein DS, Costidis AM and others (2019) Gross and histopathologic diagnoses from North Atlantic right whale Eubalaena glacialis mortalities between 2003 and 2018. Dis Aquat Org 135:1-31

* Simard Y, Lavoie D (1999) The rich krill aggregation of the Saguenay-St. Lawrence Marine Park: hydroacoustic and geostatistical biomass estimates, structure, variability, and significance for whales. Can J Fish Aquat Sci 56: 1182-1197

*van der Hoop JM, Moore MJ, Barco SG, Cole TVN and others (2013) Assessment of management to mitigate anthropogenic effects on large whales. Conserv Biol 27: 121-133

*van der Hoop JM, Corkeron P, Kenney J, Landry S, Morin D, Smith J, Moore MJ (2016) Drag from fishing gear entangling North Atlantic right whales. Mar Mamm Sci 32: 619-642

* van der Hoop JM, Corkeron P, Henry AG, Knowlton AR, Moore MJ (2017) Predicting lethal entanglements as a consequence of drag from fishing gear. Mar Pollut Bull 115:91-104

*Weinrich M (1999) Behavior of a humpback whale (Megaptera novaeangliae) upon entanglement in a gill net. Mar Mamm Sci 15:559-563

Submitted: May 5, 2020; Accepted: October 14, 2020

Proofs received from author(s): January 12, 2021 